\title{
Histopathological study of chronic wounds modulated by intermittent negative pressure therapy under limited access dressing
}

\section{Thittamaranahalli Muguregowda Honnegowda1, Pramod Kumar ${ }^{1,2}$, Rekha Singh ${ }^{3}$, Swarna Shivakumar ${ }^{4}$, Pragna Rao ${ }^{5}$, Hemanth K. Prasad ${ }^{5}$, Sudesh Kumar ${ }^{6}$, Udaya Kumar ${ }^{6}$, Echalasara Govindarama Padmanabha Udupa ${ }^{5}$}

\author{
${ }^{1}$ Department of Plastic Surgery and Burns, Kasturba Medical College, Manipal 576104, Karnataka, India. \\ ${ }^{2}$ Department of Plastic Surgery, King Abdulaziz Specialist Hospital, Sakaka 42421, Al-Jouf, Saudi Arabia. \\ ${ }^{3}$ Department of Pathology, Vydehi Institute of Medical Sciences and Research Center, Bengaluru 560066, Karnataka, India. \\ ${ }^{4}$ Department of Pathology, Apollo Hospitals, Bengaluru 560066, Karnataka, India. \\ ${ }^{5}$ Department of Biochemistry, Kasturba Medical College, Manipal 576104, Karnataka, India. \\ ${ }^{6}$ Department of Surgery, Government District Hospital, Udupi 576101, Karnataka, India.
}

Address for correspondence: Dr. Thittamaranahalli Muguregowda Honnegowda, Department of Plastic Surgery and Burns, Kasturba Medical College, Manipal 576104, Karnataka, India. E-mail: honnegowda33@gmail.com

\begin{abstract}
Aim: Negative pressure wound therapy (NPWT) has achieved widespread success in the treatment of chronic wounds. However, its effects have been only partially explored, and investigations have generally concentrated on the wound-dressing interface; a detailed histopathological description of the evolution of wounds under NPWT is still lacking. The present study was performed to investigate the effect of a limited access dressing (LAD) which exerts intermittent NPWT in a moist environment on chronic wounds. Methods: A total of 140 patients were randomized into 2 groups: LAD group $(n=64)$ and conventional dressing group $(n=76)$. By histopathological analysis of the granulation tissue, the amount of inflammatory infiltrate, necrotic tissue, angiogenesis, and extracellular matrix (ECM) deposition was studied and compared to determine healing between the 2 groups. Results: After 10 days of treatment, histopathological analysis showed a significant decrease in necrotic tissue with LAD compared to the conventional dressing group (mean \pm standard error, $11.5 \pm 0.48$ vs. $10.1 \pm 0.30, P=0.007$ ), the number of inflammatory cells (12.6 \pm 0.60 vs. $8.63 \pm 0.35, P=0.018)$, a significant increase in new blood vessels (12.8 \pm 0.58 vs. $9.3 \pm 0.29, P=0.005)$ and $\mathrm{ECM}$ deposit $(13.3 \pm 0.50$ vs. $9.6 \pm 0.24, P=0.001)$. Conclusion: LAD exerts its beneficial effects on chronic wound healing by decreasing the amount of necrotic tissue and inflammatory cells while increasing the amount of ECM deposition and angiogenesis.
\end{abstract}

Key words:

Angiogenesis, chronic wounds, extracellular matrix, granulation tissue, inflammatory cell, limited access dressing, necrotic tissue, negative pressure wound therapy

\begin{tabular}{|l|l|}
\hline \multicolumn{2}{|c|}{ Access this article online } \\
\hline Quick Response Code: & Website: \\
\hline & www.parjournal.net \\
\cline { 1 - 2 } & \\
\hline & \\
\hline
\end{tabular}

This is an open access article distributed under the terms of the Creative Commons
Attribution-NonCommercial-ShareAlike 3.0 License, which allows others to remix,
tweak, and build upon the work non-commercially, as long as the author is credited
and the new creations are licensed under the identical terms.
For reprints contact: reprints@medknow.com
$\begin{aligned} & \text { How to cite this article: Honnegowda TM, Kumar P, Singh R, } \\ & \text { Shivakumar S, Rao P, Prasad HK, Kumar S, Kumar U, Udupa EG. } \\ & \text { Histopathological study of chronic wounds modulated by intermittent } \\ & \text { negative pressure therapy under limited access dressing. Plast Aesthet } \\ & \text { Res 2015;2:272-6. } \\ & \text { Received: } 20-11-2014 \text {; Accepted: 28-01-2015 }\end{aligned}$ 


\section{INTRODUCTION}

Negative pressure wound therapy (NPWT) is a bio-stimulating treatment for chronic wounds. In recent years, it has become one of the most frequently adopted treatments for complex wounds worldwide. While it is generally believed that NPWT improves wound healing and is cost-effective, there is a persistent demand for scientific evidence.

Several recent studies support the use of NPWT to enhance wound healing by removing excess extracellular fluid and decreasing tissue edema, which leads to increased blood flow ${ }^{[1]}$ and stabilization of the wound environment. A reduction in systemic (e.g. interleukins, monocytes) and local mediators of inflammation has been demonstrated in experimental models, ${ }^{[2]}$ while decreased matrix metalloproteinase activity ${ }^{[3]}$ and bacterial burden have been documented clinically. ${ }^{[4]}$ In vivo, NPWT has been shown to increase fibroblast proliferation and migration, collagen organization, and to increase the expression of vascular endothelial growth factor and fibroblast growth factor-2, thereby enhancing wound healing. ${ }^{[5]}$

Limited access dressings (LADs) have been shown to be more effective in the treatment of chronic wounds. ${ }^{[6]}$ The present study evaluates the role of intermittent negative pressure in a moist environment using LAD (cycle of 30-min suction and 3.5-h rest) on chronic wounds by quantitative and comparative analysis of histopathological parameters including the amount of necrotic tissue, the number of inflammatory cells, extent of angiogenesis, and the level of extracellular matrix (ECM) deposit.

\section{METHODS}

\section{Ethical approval and informed consent}

This prospective randomized study was carried out in the Department of Plastic Surgery and Burns, Kasturba Medical College and Hospital, Manipal, India. The Institutional Ethics Committee reviewed and approved the study protocol. Informed consent was obtained from all patients or their next of kin (as applicable) before inclusion into the study.

\section{Clinical study design}

Two hundred and fifteen patients with chronic wounds of more than 4 weeks duration were enrolled and assessed for eligibility. After examination of inclusion criteria (nonhealing chronic wounds, 12-65 years of age) and exclusion criteria (collagen disorders, diabetes, leprosy, liver cirrhosis, HIV positive status, and pregnant women), 140 patients were randomized into the LAD group $(n=64)$ or conventional dressing group ( $n=76$ ) [Figure 1]. In the LAD group, the mean age was $38.3 \pm 10.56$ years (range: $12-60$ years), with a mean wound size at the time of admission of $19 \mathrm{~cm}^{2}$ (range: 28-40 $\mathrm{cm}^{2}$ ). In the conventional dressing group, the mean age was $35.3 \pm 14.0$ years (range: $17-65$ years) with a mean wound size at the time of admission of $18 \mathrm{~cm}^{2}$ (range: 26-39 $\mathrm{cm}^{2}$ ) [Table 1].

The LAD group was treated with intermittent negative pressure in a moist environment. The conventional closed dressing group was treated with daily dressing changes using a squeezed $5 \%$ povidone-iodine gauze which is a routine protocol in our burn unit. ${ }^{[7]}$

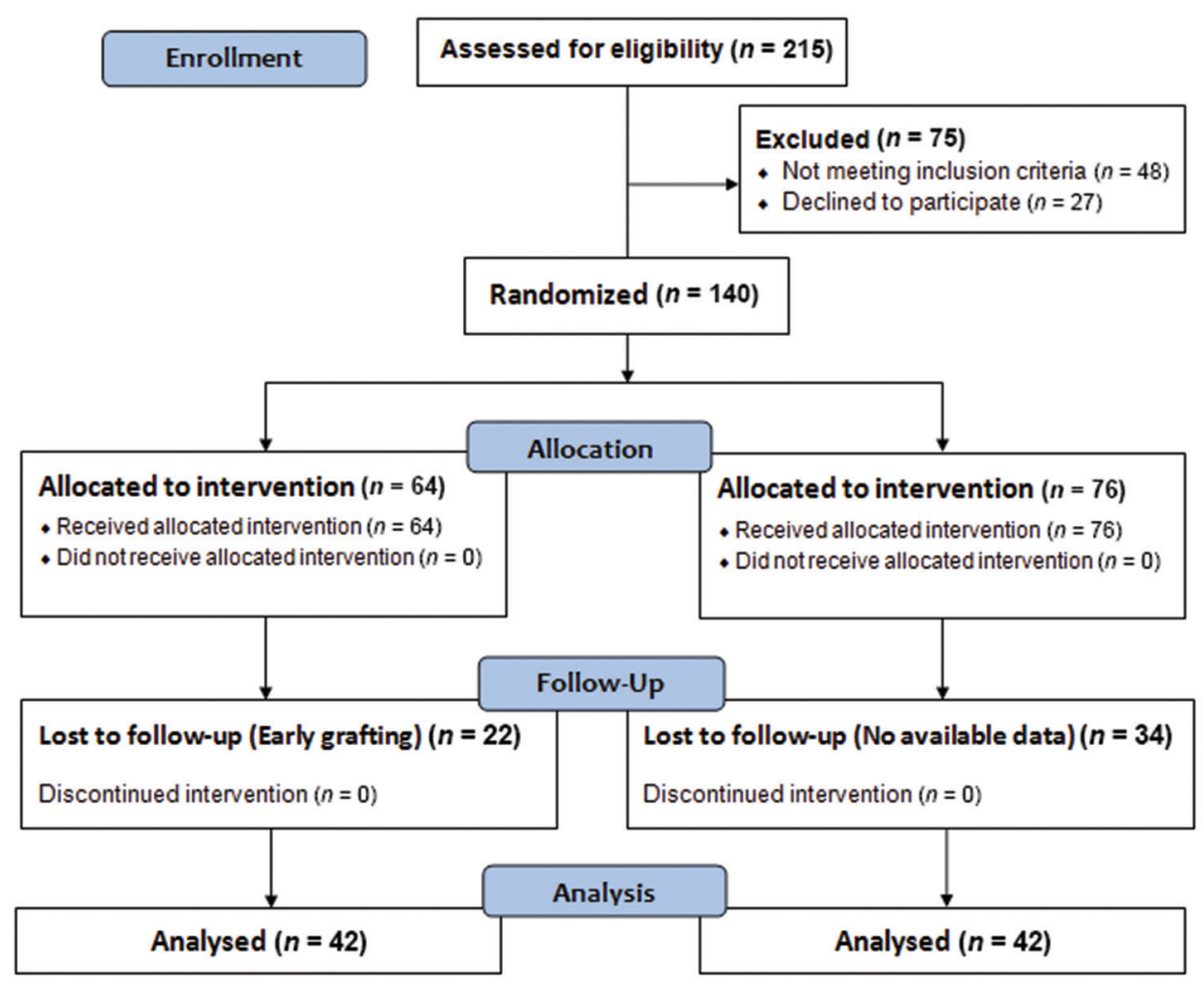

Figure 1: Consort flow chart 
Wounds were washed daily both the LAD group and the conventional group prior to dressing with $5 \%$ povidone-iodine solution. Of these 140 patients, 56 participants (22 in the LAD group and 34 in the conventional dressing group) were lost to follow-up. Of 42 patients in the LAD group, 22 (52\%) were women, and $20(48 \%)$ were men. In the conventional dressing group, 18 (42.8\%) were women, and 24 (57.1\%) were men. Biopsies were taken on days 0 and 10 and were analyzed for the histopathologic parameters under study.

\section{Randomization}

Patients were randomized by generating tables of random numbers through www.random.org. Numbers were assigned to a treatment group and sealed in opaque envelopes containing labeled paper with the treatment and patient ID.

\section{Tissue preparation for histopathologic study}

Wound biopsies performed on days 0 and 10 were collected, fixed in $10 \%$ formalin, dehydrated through an increasing alcohol series $(50 \%, 70 \%, 90 \%$, and $100 \%)$, cleared in xylene and embedded (Leica EG1150 H) in paraffin wax (melting point $56^{\circ} \mathrm{C}$ ). Serial sections of $5 \mu \mathrm{m}$ thickness were cut using a microtome (Leica RM2255) and were stained with hematoxylin-eosin (Sigma-Aldrich, MO, USA). Each section was evaluated in 8 microscopic fields $(\times 100)$ under light microscopy (Olympus PM20). Histopathology slides were graded using a modified 0-4 Ehrlich and Hunt numerical scale, and modified and internally validated in our laboratory on a scale of 1-3, with 1 representing necrosis, 2 representing inflammatory cell infiltration (white blood cell and fibroblast count), and 3 representing ECM deposition. We used a 5-point scale to evaluate the presence of necrosis and inflammatory cell infiltration $(0$, no evidence; 1 , occasional evidence; 2, light scattering; 3, abundant evidence; 4, confluent cell) as previously described, ${ }^{[8]}$ and used a 4-point scale to evaluate the presence of ECM deposition (0, no evidence; 1, little ECM deposition; 2, moderate ECM deposition; 3 , confluent ECM deposition) as previously described. ${ }^{[8]}$ In determining the degree of angiogenesis, only mature vessels were counted and identified by the presence of erythrocytes in their lumen. ${ }^{[9]}$ The score was assigned by 2 investigators. The code describing the specific treatment received by the patient was broken after scoring had been completed by the investigators.

Table 1: Patient demographics and baseline wound characterization

\begin{tabular}{|c|c|c|}
\hline Details & LAD group & $\begin{array}{l}\text { Conventional } \\
\text { group }\end{array}$ \\
\hline Number of patients & 42 & 42 \\
\hline $\begin{array}{l}\text { Age, years (mean } \pm S D \text {, } \\
\text { range) }\end{array}$ & $(38.3 \pm 10.56,12-60)$ & $(35.3 \pm 14.0,17-65)$ \\
\hline Mean wound size $\left(\mathrm{cm}^{2}\right)$ & 28 (range: 19-40) & 26 (range: 18-39) \\
\hline Female (\%) & 52 & 42.8 \\
\hline Male (\%) & 48 & 57.1 \\
\hline
\end{tabular}

LAD: Limited access dressing, SD: Standard deviation

\section{Statistical analysis}

Statistical analysis was performed using the student's $t$-test for comparisons between groups (SPSS, 15th version (233 South Wacker Drive, 11th Floor, Chicago)). The data were expressed as mean \pm standard error (SE). $P<0.05$ was considered to be significant. When appropriate, statistical uncertainty was expressed with $95 \%$ confidence levels.

\section{RESULTS}

On day 0 , both the LAD and conventional groups showed necrotic tissue with increased inflammatory infiltrates [Figures $2 \mathrm{~A}$ and $3 \mathrm{~A}$ ]. On day 10, the LAD group [Figure 2B] showed an increase in ECM deposition and angiogenesis with a decrease in inflammatory infiltrate when compared to the conventional group [Figure 3B]. The results of the histopathologic scoring are shown in Table 2. Histopathology revealed that in LAD group after 10 days of treatment, the scores of necrotic tissue $(P=0.007)$ and inflammatory cell infiltrate $(P=0.018)$ were significantly lower than those of the conventional treatment group. The score of ECM deposits and number of blood vessels on day 0 were not well-defined in either group, but on day 10 ECM deposits $(P=0.001)$ and number of blood vessel $(P=0.005)$ were significantly higher in the LAD group than in the conventional group [Table 2, Figure 4].

\section{DISCUSSION}

Wound healing is a complex and dynamic process which involves cell-cell interactions and cell-matrix interaction. The proliferative phase of wound healing is marked by angiogenesis, collagen deposition, granulation tissue formation, epithelialization, and wound contraction resulting in less scar tissue. ${ }^{[10]}$

A study by Nain et al. ${ }^{[11]}$ showed a decrease in the amount of necrotic tissue in chronic wounds treated with NPWT. Histopathological analysis showed significantly less necrotic tissue in the $\mathrm{LAD}$ group compared to a conventional dressing group after 10 days of treatment (mean $\pm \mathrm{SE}, 11.5 \pm 0.48$ vs. $10.1 \pm 0.30, P=0.007$ ). The ECM is made up of collagen fibers and glycosaminoglycans,

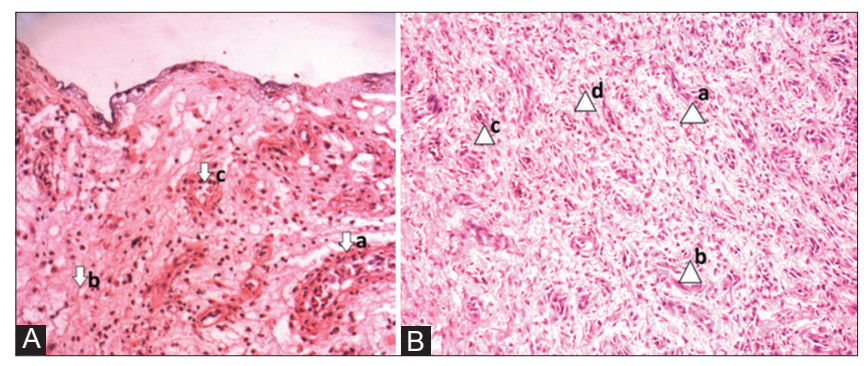

Figure 2: Histopathology of granulation tissue on days 0 and 10 in the limited access dressing (LAD) group. A: (a) LAD group - day 0 - (arrow) abundant inflammatory cells, (b) poorly developed matrix, (c) minimal blood capillaries. (photographed with an Olympus PM20 photomicroscope $\times 20$ ); B: (a) LAD group - day 10 - (arrow) increased number of fibroblast cells, (b) fewer inflammatory cells, (c) increased proliferating blood capillaries, (d) collagen bundles organized well between the cells (photographed with an Olympus PM20 photomicroscope $\times 20$ ) 


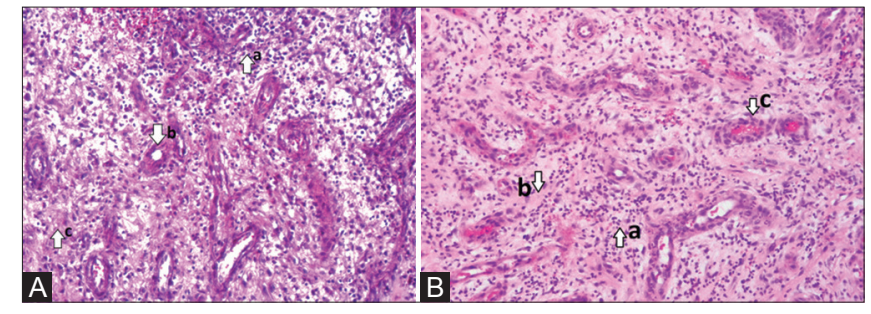

Figure 3: Histopathology of granulation tissue on days 0 and 10 in the conventional group. A: (a) Conventional group - day 0 - (arrow) abundant inflammatory cells, (b) minimal blood capillaries, (c) poor matrix (photographed with an Olympus PM20 photomicroscope $\times 20$ ); B: (a) Conventional group - day 10 - (arrow) More number of fibroblast cells, (b) poorly developed matrix with a minimal number of fibroblasts, (c) minimal blood capillaries. (photographed with an Olympus PM20 photomicroscope $\times 20$ )

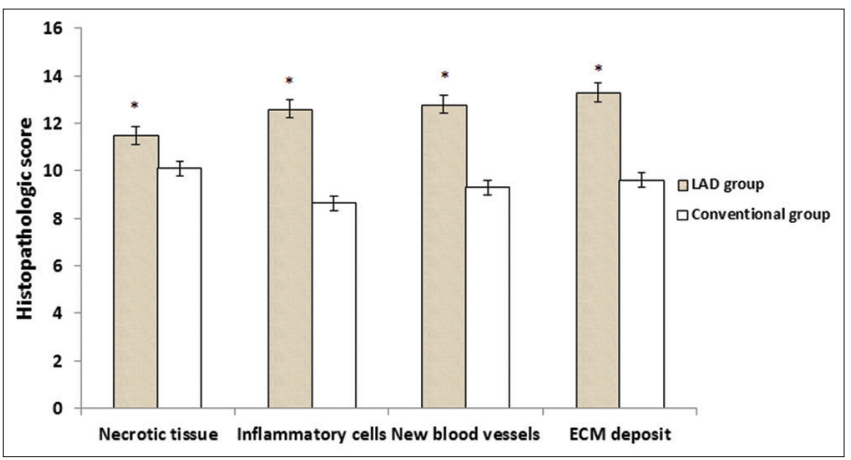

Figure 4: Histopathologic scores of necrotic tissue, inflammatory cells, new blood vessels, and extracellular matrix deposit in limited access dressing versus conventional groups (mean $\pm \mathrm{SE}, P<0.05$ )

Table 2: Histopathologic scores of LAD and conventional groups

\begin{tabular}{|c|c|c|c|c|c|c|c|}
\hline \multirow[t]{3}{*}{ Parameters } & \multicolumn{6}{|c|}{$(n=42)($ mean \pm SE) } & \multirow[t]{3}{*}{$\boldsymbol{P}$} \\
\hline & \multicolumn{3}{|c|}{ LAD group } & \multicolumn{3}{|c|}{ Conventional dressing group } & \\
\hline & Day 0 & Day 10 & Day $(0-10)$ & Day 0 & Day 10 & Day $(0-10)$ & \\
\hline Necrotic tissue & $25.5 \pm 0.86$ & $14.0 \pm 0.39$ & $11.5 \pm 0.48$ & $26.1 \pm 0.76$ & $16.0 \pm 0.46$ & $10.1 \pm 0.30$ & $0.007^{*}$ \\
\hline Inflammatory cells & $25.0 \pm 0.74$ & $12.4 \pm 0.45$ & $12.6 \pm 0.60$ & $17.0 \pm 0.34$ & $8.37 \pm 0.35$ & $8.63 \pm 0.35$ & $0.018^{*}$ \\
\hline New blood vessels & $8.3 \pm 0.45$ & $21.1 \pm 0.63$ & $12.8 \pm 0.58$ & $8.0 \pm 0.24$ & $17.3 \pm 0.56$ & $9.3 \pm 0.29$ & $0.005^{*}$ \\
\hline ECM deposit & $9.7 \pm 0.67$ & $23.0 \pm 0.78$ & $13.3 \pm 0.50$ & $8.4 \pm 0.29$ & $18.0 \pm 0.46$ & $9.6 \pm 0.24$ & $0.001^{*}$ \\
\hline
\end{tabular}

Each parameter was assessed individually in 8 microscopic fields per slide. The scores of the 8 microscopic fields were totaled, and the mean \pm SE were calculated, respectively; $* P<0.05$ significant difference. Histological scales: 0 , no evidence; I, occasional evidence; 2, light scattering; 3 , abundant evidence, and 4, confluent cells or fibers. LAD: Limited access dressing, SE: Standard error, ECM: Extracellular matrix

which form the principal component of connective tissue and play a central role in wound healing by providing a structural framework for regenerating tissue. ${ }^{[12]}$

Borgquist et al. ${ }^{[13]}$ showed that chronic wounds treated with NPWT promote the formation of granulation tissue with an increase in ECM. After 10 days of treatment, there was a significant increase in the ECM deposit of a LAD group compared to a conventional group (mean $\pm \mathrm{SE}$, $13.3 \pm 0.50$ vs. $9.6 \pm 0.24, P=0.001)$.

Angiogenesis improves circulation to the wound bed by providing oxygen and essential nutrients for the healing process. ${ }^{[14]}$ Xia et al. ${ }^{[15]}$ conducted a study on chronic wounds treated with NPWT, and showed that NPWT-treated wounds had increased angiogenesis and blood flow, with the number of new blood vessels significantly higher in a LAD group when compared to a conventional dressing group (mean $\pm \mathrm{SE}, 12.8 \pm 0.58$ vs. $9.3 \pm 0.29, P=0.005$ ).

Huang et al. ${ }^{1616}$ showed that NPWT promotes healing by modulating inflammation and cell migration. There were significantly fewer inflammatory cells in a LAD group as compared to a conventional dressing group (mean $\pm \mathrm{SE}$, $12.6 \pm 0.60$ vs. $8.63 \pm 0.35, P=0.018)$.

In conclusion, the present study demonstrates that intermittent NPWT in a moist environment with a LAD to chronic wounds accelerates the rate of wound healing by significantly increasing ECM deposits and the formation of new blood vessels while decreasing the number of inflammatory cells and the amount of necrotic tissue.

\section{Financial support and sponsorship}

Nil.

Conflicts of interest

There are no conflicts of interest.

\section{REFERENCES}

I. Rahmanian-Schwarz A, Willkomm LM, Gonser P, Hirt B, Schaller HE. A novel option in negative pressure wound therapy (NPWT) for chronic and acute wound care. Burns 20I2;38:573-7.

2. Norbury K, Kieswetter K.Vacuum-assisted closure therapy attenuates the inflammatory response in porcine acute wound healing model. Wounds 2007;19:97-106.

3. Greene AK, Puder M, Roy R, Arsenault D, Kwei S, Moses MA, Orgill DP. Microdeformational wound therapy: effects on angiogenesis and matrix metalloproteinases in chronic wounds of 3 debilitated patients. Ann Plast Surg 2006;56:418-22.

4. Mouës CM, Vos MC, van den Bemd GJ, Stijnen T, Hovius SE. Bacterial load in relation to vacuum-assisted closure wound therapy: a prospective randomized trial. Wound Repair Regen 2004;12:1।-7.

5. Jacobs S, Simhaee DA, Marsano A, Fomovsky GM, Niedt G, Wu JK. Efficacy and mechanisms of vacuum-assisted closure (VAC) therapy in promoting wound healing: a rodent model. J Plast Reconstr Aesthet Surg 2009;62:133 I-8.

6. Kumar P. Exploiting potency of negative pressure in wound dressing using limited access dressing and suction-assisted dressing. Indian J Plast Surg 2012;45:302-15

7. Balin AK, Pratt L. Dilute povidone-iodine solutions inhibit human skin fibroblast growth. Dermatol Surg 2002;28:210-4.

8. Turan M, Saraydýn SU, Bulut HE, Elagöz S, Cetinkaya O, Karadayi K, Canbay E, Sen M. Do vascular endothelial growth factor and basic fibroblast growth factor promote phenytoin's wound healing effect in rat? An immunohistochemical and histopathologic study. Dermatol Surg 2004;30:1303-9.

9. Galeano M, Altavilla D, Cucinotta D, Russo GT, Calò M, Bitto A, Marini $H$, Marini R, Adamo EB, Seminara P, Minutoli L, Torre V, Squadrito F. Recombinant human erythropoietin stimulates angiogenesis and wound healing in the genetically diabetic mouse. Diabetes 2004;53:2509-17. 
10. Al-Bayaty F, Abdulla MA. A comparison of wound healing rate following treatment with aftamed and chlorine dioxide gels in streptozotocin-induced diabetic rats. Evid Based Complement Alternat Med 2012;201 2:468764.

II. Nain PS, Uppal SK, Garg R, Bajaj K, Garg S. Role of negative pressure wound therapy in healing of diabetic foot ulcers. J Surg Tech Case Rep 2011;3:17-22.

12. Abdulla MA, Ahmed KA, Ali HM, Noor SM, Ismail S. Wound healing activities of rafflesia hasseltii extract in rats. J Clin Biochem Nutr 2009;45:304-8.

13. Borgquist $O$, Ingemansson $R$, Malmsjö $M$. The effect of intermittent and variable negative pressure wound therapy on wound edge microvascular blood flow. Ostomy Wound Manage 2010;56:60-7.

14. Suguna L, Sivakumar P, Chandrakasan G. Effects of Centella asiatica extract on dermal wound healing in rats. Indian J Exp Biol 1996;34: I 208-II.

15. Xia CY,Yu AX, Qi B, Zhou M, Li ZH, Wang WY. Analysis of blood flow and local expression of angiogenesis-associated growth factors in infected wounds treated with negative pressure wound therapy.Mol Med Rep 2014;9: I 749-54.

16. Huang C, Leavitt T, Bayer LR, Orgill DP. Effect of negative pressure wound therapy on wound healing. Curr Probl Surg 20 I4;5I:30 I-3I. 